\title{
ANÁLISES FÍSICO-QUÍMICAS DE PRÉ-MISTURAS DE PÃES DE QUEIJO E PRODUÇÃO DE PÃES DE QUEIJO COM ADIÇÃO DE OKARA
}

\author{
Physicochemical analyses of commercial samples of cheese bread premix and \\ production of cheese breads with addition of okara
}

\author{
Krischina Singer Aplevicz ${ }^{1}$, Ivo Mottin Demiate ${ }^{2}$
}

\begin{abstract}
RESUMO
Okara, ou resíduo de soja, é um subproduto do processamento do extrato aquoso de soja e do tofu. Pão de queijo é um produto assado ao forno obtido a partir da mistura de polvilho com água ou leite, queijo, sal e gordura, podendo ser utilizados polvilho doce, azedo ou a mistura deles. Objetivou-se com este trabalho caracterizar pré-misturas comerciais de pão de queijo por intermédio de análises físico-químicas e também avaliar a qualidade de pães de queijo produzidos com a adição de subproduto da obtenção do extrato aquoso de soja. As características de qualidade de pães de queijo suplementados com 5,10 e $15 \%$ de okara foram investigadas. Os pães de queijo suplementados com subproduto okara apresentaram teores de proteínas e de fibras alimentares superiores ao controle. Os produtos panificados foram submetidos à análise sensorial de aceitabilidade utilizando-se a escala hedônica de nove pontos, com provadores não-treinados. Amostras de pães de queijo com 5, 10 e 15\% de okara não foram consideradas diferentes significativamente em nível de $5 \%$ e tiveram boa aceitação.
\end{abstract}

Termos para indexação: Polvilho azedo, pão de queijo, okara.

\section{ABSTRACT}

Okara, or soy residue, is a byproduct of soy aqueous extract and tofu manufacturing. Cheese bread is a Brazilian specialty made by blending cassava starch (cassava starch or sour cassava starch) water or milk, cheese, salt and fat and is baked on oven. This study has the objective of characterizing cheese breads made with addition of okara. Additionally in this work commercial samples of cheese bread premix were compared in terms of physicochemical properties. The quality characteristics of cheese breads supplemented with 5, 10 and $15 \%$ of okara were investigated. The results showed that the cheese breads supplemented with the byproduct okara had an increase in the protein and dietary fiber contents. The samples were submitted to an acceptability sensory evaluation with a nine point hedonic scale, involving untrained panelists. The cheese breads made with 5, 10 and $15 \%$ of okara were not statistically different at the level $5 \%$ and had good acceptability.

Index terms: Sour cassava starch, cheese bread, okara.

(Recebido em 5 de setembro de 2006 e aprovado em 21 de junho de 2007)

\section{INTRODUÇÃo}

A soja (Glycine max), pertencente à família Fabaceae, é uma semente oleaginosa, com aproximadamente $40 \%$ de proteínas, aminoácidos essenciais, cálcio, fósforo, ferro, vitaminas A e do complexo B (B1, B2 e B6) (HALL, 1971). Em 2004, o Brasil foi o segundo maior produtor mundial de soja, com produção de 50 milhões de toneladas ou $25 \%$ da safra mundial, estimada em 200 milhões de toneladas (EMBRAPA, 2007).

A Food and Drug Administration (FDA) relata que a ingestão de $25 \mathrm{~g}$ de proteína de soja por dia, associada a uma dieta com pouca gordura saturada e colesterol, pode reduzir o risco de doenças cardíacas. Alimentos com soja contêm proteínas que reduzem o nível de colesterol ruim (LDL) e aumentam o nível de colesterol bom (HDL) (ANDERSON et al., 1995). Uma alternativa viável é estimular o consumo de produtos de soja, que são fontes protéicas nutritivas, econômicas e disponíveis no mercado (CARRÃO-PANIZZI \& MANDARINO, 1998).

A soja dá origem a diversos produtos e subprodutos sendo alguns exemplos o tofu ("queijo de soja"), farinhas e farelos de soja, extrato aquoso de soja ("leite de soja") e o resíduo do extrato aquoso da soja, denominado okara ou resíduo de soja (BOWLES, 2005). O okara é um subproduto do processamento do extrato aquoso de soja e do tofu e contém aproximadamente $27 \%$ de proteínas (base seca) com boa qualidade nutricional (WANG \& CAVINS, 1989), sendo considerado uma fonte vegetal de baixo custo e bom potencial para consumo humano.

No processamento da soja, a etapa de imersão dos grãos na água visando ao seu amaciamento é quase sempre necessária, e o tratamento térmico adequado da soja

\footnotetext{
${ }^{1}$ Mestre, Professora Efetiva - Centro Federal de Educação Tecnológica de Santa Catarina/CEFET-SC - Rua 14 de Julho, 150, Coqueiros - 88075-010 Florianópolis, SC - krischina@cefetsc.edu.br

'Doutor, Professor Adjunto - Departamento de Engenharia de Alimentos/DEA - Universidade Estadual de Ponta Grossa/UEPG - Avenida Carlos Cavalcanti, 4748, Uvaranas - 84030-900 - Ponta Grossa, PR - demiate@yahoo.com
} 
aumenta a digestibilidade de sua proteína, bem como inativa os inibidores de proteases e outros fatores antinutricionais. $\mathrm{O}$ tratamento térmico das leguminosas é eficaz para inativar substâncias antinutricionais, embora possa ocorrer atividade residual significativa de inibidores de proteases em produtos da soja, após tratamento térmico (BAYRAM et al., 2004).

Jackson et al. (2001) concluíram que aproximadamente um terço do conteúdo de isoflavonas da soja é transferida ao okara. Em razão da concentração protéica dele ser semelhante a dos grãos de soja, o okara apresenta um grande potencial para ser utilizado como fonte de nutrientes e isoflavonas.

A suplementação de produtos alimentícios com okara foi relatada por Waliszewski et al. (2002). Os autores realizaram uma avaliação química e sensorial de okara incorporado em porcentagens de 5, 10, 15, 20 e 25\% em Tortillas. Por meio do estudo, os autores demonstraram que concentrações de até $10 \%$ de okara podem ser adicionadas às Tortillas, alcançando níveis satisfatórios de aceitação.

Pão de queijo é um produto tradicionalmente mineiro, obtido a partir da mistura de polvilho com água ou leite, queijo, sal e gordura, podendo variar o tipo de polvilho (doce, azedo ou a mistura deles). Além de ser uma fonte reconhecida de carboidratos, o pão de queijo também é um produto de panificação isento de glúten, o que o coloca como alimento alternativo para pacientes celíacos, alérgicos às proteínas do trigo (PEREIRA et al., 2004).

Pereira (1998) afirmou que o assamento da massa define a qualidade do pão de queijo, pois ocorre aumento do volume por causa da expansão de vapor e ar. As principais modificações que ocorrem nessa fase são a evolução e expansão dos gases, coagulação das proteínas dos ovos, leite e queijo, gelatinização do amido, desidratação parcial do produto pela evaporação da água, desenvolvimento de sabores; mudanças de cor em virtude da Maillard entre as proteínas do leite, queijo e ovos com açúcares redutores, bem como a outras reações químicas, formação da crosta pela desidratação da superfície, escurecimento da crosta por causa da reação de Maillard e caramelização dos açúcares, alterações drásticas nas propriedades do amido pela formação de novas substâncias como açúcares caramelizados, pirodextrinas, e compostos que conferem ao produto assado boas propriedades sensoriais.

Este trabalho teve como objetivo avaliar a composição química em amostras comerciais de prémisturas de pães de queijo e a qualidade daqueles produzidos com a adição do resíduo do extrato aquoso de soja (okara).

\section{MATERIAL E MÉTODOS}

\section{Material}

Foram adquiridas nove amostras de pré-misturas de pães de queijo em supermercados, sendo que o polvilho azedo utilizado neste trabalho foi cedido pela empresa Pinduca. Os ingredientes utilizados foram adquiridos no comércio local dos Campos Gerais (PR) e o okara foi obtido em laboratório pela produção de extrato aquoso de soja (Figura 1).

Os grãos foram submetidos ao branqueamento utilizando água a $98{ }^{\circ} \mathrm{C} / 5$ minutos, sendo em seguida resfriados pelo mesmo tempo. A obtenção do extrato obedeceu a proporção de soja : água em 1:10, ou seja, 100g

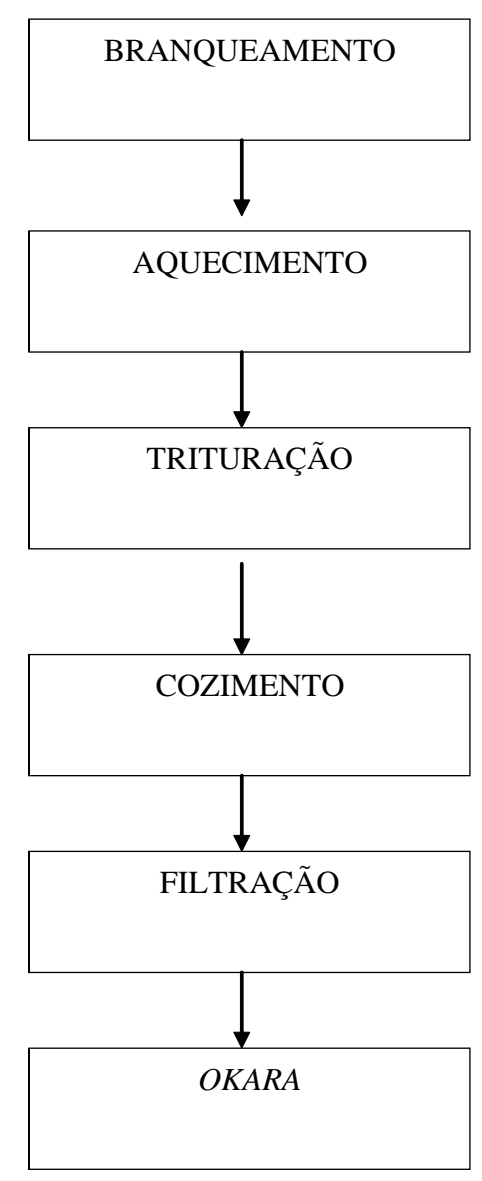

FIGURA 1 - Fluxograma de obtenção do okara. 
de soja para 1 litro de água (CIABOTTI et al., 2006). Os grãos foram aquecidos por 5 minutos, triturados em liquidificador, cozidos novamente por 10 minutos e filtrados em peneira de 80 mesh. O líquido filtrado foi considerado como extrato de soja e a massa restante, resíduo de soja.

Análises físico-químicas das pré-misturas, pães de queijo e okara

Os teores de umidade, cinzas, lipídios e proteínas das pré-misturas, pães de queijo e okara foram determinados de acordo com a metodologia do Instituto Adolfo Lutz (1985).

Determinação de fibras alimentares dos pães de queijo e okara

O total de fibra alimentar dos pães de queijo e do okara foi determinado utilizando-se o método enzimático e gravimétrico. A metodologia utilizada foi adaptada da AOAC (1997) e se fundamenta no fato de que amostras secas, livres de gordura, são gelatinizadas em presença de alfa-amilase termoestável, digeridas enzimaticamente com protease e amiloglucosidase para a remoção da proteína e do amido presentes no material. Adiciona-se etanol para precipitar a fibra dietética solúvel. O resíduo é então filtrado e lavado com etanol e acetona. Após a secagem, o resíduo é pesado. Uma parte da amostra é utilizada para análise de proteínas e a outra para análise de cinzas. $\mathrm{O}$ total de fibras dietéticas é o peso do resíduo subtraído dos teores de proteínas e de cinzas.

\section{Determinação do $\mathrm{pH}$ das pré-misturas de pães de queijo}

Para determinação do $\mathrm{pH}, 20 \mathrm{~g}$ de pré-mistura de pães de queijo foram dispersos em $100 \mathrm{~mL}$ de água deionizada e a suspensão foi agitada por 30 minutos (SMITH, 1967). Após a suspensão foram centrifugadas por 2 minutos. O líquido sobrenadante foi decantado, sendo pesados $30 \mathrm{~g}$ em um béquer, e em seguida determinando o pH em potenciômetro (Hanna Instruments, mod. HI 8424, Woonsocket RI, USA).

Determinação da acidez titulável das pré-misturas de pães de queijo

A análise foi realizada no mesmo material usado para determinação do $\mathrm{pH}$, conforme descrito por PlataOviedo (1998). Após a determinação do pH foram adicionadas duas a quatro gotas de fenolfetaleína. A mistura foi novamente agitada enquanto $\mathrm{NaOH} 0,1 \mathrm{~N}$ era adicionado, até que o $\mathrm{pH}$ atingisse 8,3. O resultado foi expresso em g de ácido láctico por $100 \mathrm{~g}$ de amostra.
Propriedade de expansão das pré-misturas e dos pães de queijo

$\mathrm{Na}$ obtenção das massas para avaliação da propriedade de expansão, $12 \mathrm{~g}$ de pré-mistura de pães de queijo foram parcialmente gomificadas com $10 \mathrm{~mL}$ de água deionizada em ebulição. Após a homogeneização manual, a massa foi dividida em três esferas com pesos iguais, sendo levadas a um forno elétrico pré-aquecido a $200^{\circ} \mathrm{C}$ e assadas por 25 minutos. Ao final desse período, após resfriarem, as esferas expandidas foram pesadas. Essas esferas foram impermeabilizadas com parafina fundida e seus volumes medidos pelo deslocamento de água em proveta graduada. O resultado da expansão foi expresso em volume específico, em mL/g (DEMIATE \& CEREDA, 2000).

\section{Elaboração dos produtos panificados}

Foram desenvolvidas três formulações de pães de queijo utilizando as concentrações de 5,10 e $15 \%$ do subproduto okara, com umidade de $2 \%$, em adição ao polvilho na formulação base do pão de queijo. Tais concentrações foram estabelecidas de acordo com testes prévios e também a partir de dados de literatura onde o subproduto foi utilizado (BOWLES, 2005; WALISZEWSKI et al., 2002). A porcentagem dos ingredientes nas formulações de pães de queijo suplementados com 5, 10 e $15 \%$ em relação ao polvilho encontra-se na Tabela 1.

TABELA 1 - Quantidades dos ingredientes utilizados nas formulações de pães de queijo suplementados com 5, 10 e $15 \%$ de okara.

\begin{tabular}{lccc}
\hline \multicolumn{4}{c}{ Quantidades (g) } \\
\hline Ingredientes & $\begin{array}{c}\mathbf{5 \%} \\
\text { okara }\end{array}$ & $\begin{array}{c}\mathbf{1 0 \%} \\
\text { okara }\end{array}$ & $\begin{array}{c}\mathbf{1 5 \%} \\
\text { okara }\end{array}$ \\
\hline Polvilho & 160 & 160 & 160 \\
Leite & 50 & 50 & 50 \\
Água & 50 & 50 & 50 \\
Óleo & 30 & 30 & 30 \\
Sal & 2,4 & 2,4 & 2,4 \\
Ovo líquido & 55 & 55 & 55 \\
Queijo & 80 & 80 & 80 \\
okara & 8 & 16 & 24 \\
\hline
\end{tabular}


Análise sensorial dos pães de queijo suplementados com 5,10 e $15 \%$ de okara

A análise sensorial dos produtos foi realizada por meio do teste de aceitação (FARIA \& YOTSUYANAGI, 2002). Cada amostra foi testada por um grupo de oitenta e cinco provadores não-treinados, que marcaram em uma ficha a impressão que o produto, como um todo, lhes causou. Para o teste foi utilizada uma escala hedônica de 9 pontos $(9=$ gostei muitíssimo, 5 = indiferente, $1=$ desgostei muitíssimo). As expressões foram convertidas a valores numéricos e analisadas.

Foi realizado teste de intenção de compra da amostra com pão de queijo suplementado com $15 \%$ de okara, em função de suas características nutricionais favoráveis. Nele a escala utilizada foi de 5 pontos $(5=$ certamente compraria, 3 = indiferente, 1 = certamente não compraria) (DELLA TORRE et al., 2003).

\section{Análise estatística}

Os dados obtidos foram submetidos à análise de variância e as médias comparadas pelo Teste de Tukey, utilizando-se o programa Microsoft Excel versão 2001. Para as amostras obtidas nesse estudo o produto foi considerado aceito quando a nota média da análise sensorial correspondeu a $7 \pm 0,5$, conforme Stone \& Sidel (1993).

\section{RESULTADOS E DISCUSSÃO}

As pré-misturas apresentam algumas vantagens em sua utilização por panificadoras, supermercados, lanchonetes, dentre as quais o barateamento da formulação, agilidade do processamento e padronização da qualidade dos produtos finais. As pré-misturas de pão de queijo consideradas nesse estudo tinham prazos de validade impressos nas embalagens que variavam entre três, seis e oito meses. Verificam-se na Tabela 2, os dados da caracterização físico-química das pré-misturas de pão de queijo.

O teor de proteínas apresentou variação entre as amostras, de 0,35 a 3,85\%, com uma amplitude de 3,50. Essa variação está relacionada, possivelmente, às diferentes proporções de queijo e leite nas pré-misturas.

Para a fração cinzas das pré-misturas foram obtidos resultados próximos. A média das pré-misturas de pão de queijo foi de $3,11 \%$. Os carboidratos totais representam mais de dois terços da composição das pré-misturas de pão de queijo, comprovando a importância do polvilho para o produto.

Uma das amostras apresentou 1,33\% de lipídios. No rótulo do produto consta a necessidade de acrescentar gordura para a elaboração do pão de queijo.

Pereira (1998) analisou amostras de pão de queijo congelado e a composição centesimal média encontrada foi $31 \%$ de umidade, $13 \%$ de proteínas, $21 \%$ de lipídios, $4 \%$ de cinzas, $30 \%$ de carboidratos e $1 \%$ de fibras.

As pré-misturas de pão de queijo apresentaram valores de $\mathrm{pH}$ entre 5,72 a 7,30, com coeficiente de variação de $9,31 \%$. Os resultados são compatíveis com os dados citados por Pereira (2001). A média encontrada para acidez titulável foi de $0,19 \mathrm{~g}$ de ácido lático/ $100 \mathrm{~g}$ de amostra, com uma amplitude de 0,37.

As amostras de pão de queijo analisadas apresentaram valores de expansão médio de $2,42 \mathrm{~mL} / \mathrm{g}$, com uma amplitude de 1,19. Essa variação pode ser explicada pelo fato do pão de queijo ainda não ser um produto com uma tecnologia padronizada e de que os

TABELA 2 - Valores médios da composição química de alguns parâmetros físico-químicos das pré-misturas de pão de queijo.

\begin{tabular}{lcccccc}
\hline $\mathbf{N}=\mathbf{9}$ & \multicolumn{3}{c}{} & \multicolumn{3}{c}{ Estatística descritiva } \\
\hline Parâmetros analisados & $\begin{array}{c}\text { Valores } \\
\text { médios }\end{array}$ & Mínimo & Máximo & Amplitude & $\begin{array}{c}\text { Desvio } \\
\text { Padrão }\end{array}$ & C.V.\% \\
\hline Umidade $\mathrm{g} / 100 \mathrm{~g}(\%)$ & 8,53 & 6,76 & 9,66 & 2,90 & 0,99 & 11,56 \\
Cinzas $\mathrm{g} / 100 \mathrm{~g}(\%)$ & 3,11 & 2,23 & 4,12 & 1,89 & 0,68 & 21,90 \\
Proteína $\mathrm{g} / 100 \mathrm{~g}(\%)$ & 1,58 & 0,35 & 3,85 & 3,50 & 1,00 & 63,28 \\
Lipídios $\mathrm{g} / 100 \mathrm{~g}(\%)$ & 13,23 & 1,33 & 21,44 & 20,11 & 5,41 & 40,87 \\
Carboidratos g/100g(\%) * & 73,56 & 64,98 & 83,86 & 18,88 & 5,08 & 6,90 \\
$\mathrm{pH}$ & 6,49 & 5,72 & 7,30 & 1,58 & 0,60 & 9,31 \\
Acidez $(\mathrm{g}$ ac.lático/100g amostra) & 0,19 & 0,01 & 0,38 & 0,37 & 0,13 & 69,46 \\
Expansão $(\mathrm{mL} / \mathrm{g})$ & 2,42 & 2,01 & 3,20 & 1,19 & 0,39 & 16,08 \\
\hline
\end{tabular}

*Por diferença 
fabricantes, em busca de um produto de melhor qualidade e menor custo, realizam alterações nas formulações.

Os resultados encontrados confirmam a falta de padronização dos produtos, sobretudo em algumas matérias-primas como o polvilho e o queijo. O problema da falta de padronização e qualidade microbiológica dos queijos é tão relevante que alguns fabricantes de médio porte chegam a importar queijo para a produção do pão de queijo, o que pode levar a uma descaracterização do produto original, pois o queijo tipo Minas Curado é tradicionalmente usado na fabricação desse produto. Além disto, a utilização do leite cru na fabricação do queijo artesanal pode resultar no crescimento de Staphylococcus aureus, microrganismo que produz uma toxina termoestável, a que por não ser destruída na temperatura de assamento do pão de queijo, pode representar um risco à saúde do consumidor (PEREIRA, 2001).

A composição centesimal média do okara revelou valores próximos daqueles encontrados na literatura (Tabela 3). Os carboidratos representam $35,12 \%$, e do conteúdo de carboidratos, $30,20 \%$ representam as fibras alimentares da amostra.

TABELA 3 - Composição centesimal do okara dessecado.

\begin{tabular}{cc}
\hline Okara & $\mathbf{g} / \mathbf{1 0 0 g}(\boldsymbol{\%})$ \\
\hline Umidade & $2,00 \pm 0,13$ \\
Cinzas & $3,90 \pm 0,16$ \\
Gordura & $17,01 \pm 0,02$ \\
Proteína & $41,97 \pm 0,18$ \\
Fibra alimentar & $30,20 \pm 1,06$ \\
Carboidratos * & 35,12 \\
\hline
\end{tabular}

Bowles (2005) encontrou 37\% de proteínas, $13 \%$ lipídios, $2,8 \%$ cinzas e $42,5 \%$ de fibras alimentares em base seca no subproduto okara. Ma et al. (1997) encontraram valores para o okara seco de aproximadamente $26,8 \%$ de proteínas, 52,9\% de carboidratos e $12,3 \%$ de gordura.

Foram produzidas três formulações de pão de queijo com 5, 10 e $15 \%$ de okara seco. Os resultados da avaliação da qualidade físico-química dos pães de queijo com okara, ilustram-se na Tabela 4.

Pode-se observar que com a adição do subproduto okara existe um aumento na concentração de cinzas, lipídios, proteínas e fibra alimentar nos pães de queijo. Com relação ao conteúdo de fibra alimentar das diferentes formulações, pode-se observar um acréscimo de uma formulação à outra com o aumento da concentração do subproduto. Assim, pode-se considerar que os produtos suplementados com okara em qualquer uma das concentrações usadas acabam tendo certo enriquecimento em fibras.

As amostras de 5, 10 e 15\% apresentaram valores de expansão sucessivamente menores, sendo que as amostras de pão de queijo com 10 e $15 \%$ de okara apresentaram valores próximos de expansão. Na Tabela 5, podem-se observar as notas atribuídas aos pães de queijo contendo 5, 10 e $15 \%$ de okara no teste de aceitabilidade.

Por meio das observações dos resultados da análise sensorial de aceitabilidade dos pães de queijo suplementados com 5,10 e $15 \%$ de okara e as médias obtidas pode-se constatar que todos os pães de queijo elaborados com okara foram aceitos.

Foi realizado um teste para verificação da intenção de compra das amostras de pão de queijo (Figura 2).

TABELA 4 - Composição centesimal $(\mathrm{g} / 100 \mathrm{~g})$ em matéria úmida e expansão de pães de queijo elaborados com 5, 10 e $15 \%$ de okara.

\begin{tabular}{lccccccc}
\hline & Umidade & Cinzas & Lipídios & Proteína & $\begin{array}{c}\text { Carboidratos } \\
\text { Totais* }\end{array}$ & $\begin{array}{c}\text { Fibra } \\
\text { Alimentar }\end{array}$ & $\begin{array}{c}\text { Expansão } \\
\text { mL/g }\end{array}$ \\
\hline 5\% okara & $26,4 \pm 3,1$ & $1,8 \pm 0,1$ & $15,1 \pm 0,5$ & $10,4 \pm 0,4$ & 46,3 & $9,9 \pm 0,9$ & $4,6 \pm 0,3$ \\
& & $1,9 \pm$ & & & & & \\
10\% okara & $28,4 \pm 0,9$ & 0,03 & $16,3 \pm 0,2$ & $11,3 \pm 0,2$ & 42,1 & $11,6 \pm 1,1$ & $2,7 \pm 0,1$ \\
15\% okara & $30,1 \pm 2,6$ & $2,0 \pm 0,1$ & $17,4 \pm 1,7$ & $11,7 \pm 0,3$ & 38,8 & $13,2 \pm 0,8$ & $2,4 \pm 0,5$ \\
\hline
\end{tabular}

* Determinado por diferença 
TABELA 5 - Médias da aceitabilidade das amostras de pães de queijo suplementados com 5, 10 e 15\% do subproduto okara.

\begin{tabular}{cc}
\hline $\begin{array}{c}\text { Okara (\%) adicionado ao } \\
\text { pão de queijo }\end{array}$ & $\begin{array}{c}\text { Aceitabilidade } \\
\text { (nota média) }\end{array}$ \\
\hline 5 & $6,92^{\mathrm{a}}$ \\
10 & $7,04^{\mathrm{a}}$ \\
15 & $6,95^{\mathrm{a}}$ \\
\hline
\end{tabular}

*médias seguidas de letras distintas, diferem entre si, pelo Teste de Tukey, em nível de 5\%.

* o produto foi considerado aceito quando a nota média correspondeu a $7 \pm 0,5$, conforme Stone e Sidel (1993).

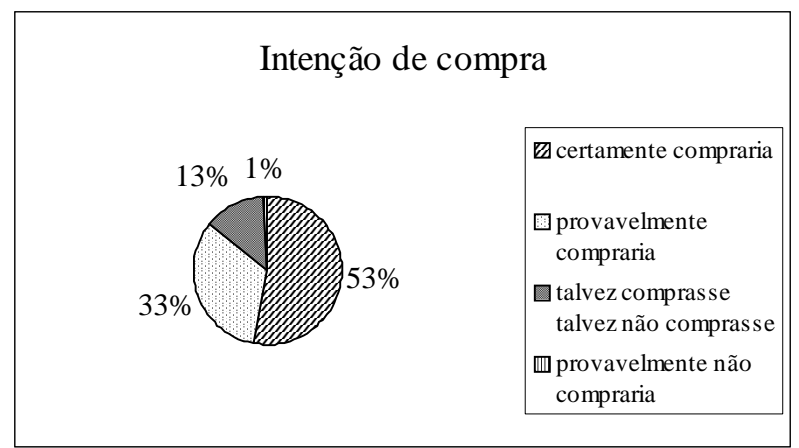

FIGURA 2 - Intenção de compra do pão de queijo elaborado com $15 \%$ de okara.

Observando-se as medidas de volume das amostras pode-se admitir que o pão de queijo com 15\% de okara teve um volume inferior, mas optou-se por considerá-lo, nas análises, em função de suas características nutricionais favoráveis. Para o pão de queijo com 15\% de okara o resultado foi que $53 \%$ dos provadores certamente comprariam o produto e $33 \%$ provavelmente o comprariam.

Dhingra \& Jood (2001) afirmaram que pães de trigo suplementados com 15\% de farinha de soja atingiram um bom grau de aceitação sensorial. Os autores verificaram que a farinha obtida do resíduo okara tinha teor de fibras superior à farinha de soja, e constataram que sua aceitação sensorial foi mais difícil assim, concentrações inferiores a $15 \%$ foram as mais indicadas.

Bowles (2005) aplicou 5, 10 e 15\% do subproduto okara em pão do tipo francês e concluiu que as amostras contendo 5 e $10 \%$ não diferiram significativamente. O autor realizou teste de intenção de compra dos produtos panificados com $10 \%$ de okara, e do ponto de vista dos provadores a amostra foi aprovada. O autor destaca a qualidade nutricional superior do produto obtido com a adição de $10 \%$ de okara em relação ao controle, sem qualquer adição do subproduto.

\section{CONCLUSÕES}

As análises físico-químicas de pré-misturas comerciais de pão de queijo demonstram a falta de padronização dos produtos.

A adição de okara contribuiu no aumento da concentração de lipídios, cinzas, proteínas e fibra alimentar nos pães de queijo. Os produtos suplementados com okara, em todas as concentrações usadas, tiveram enriquecimento em fibras.

Os pães de queijo elaborados com 5, 10 e $15 \%$ de okara não apresentaram diferença significativa em relação à análise sensorial de aceitabilidade. Observando-se as medidas de volume das amostras verificou-se que o pão de queijo com $15 \%$ de okara teve um volume inferior, entretanto optou-se por considerá-lo na análise sensorial em função de apresentar o maior teor de fibra alimentar. O pão de queijo adicionado de 15 \% de okara teve uma avaliação favorável em relação à intenção de compra.

\section{AGRADECIMENTOS}

Agradecemos a Coordenação de Aperfeiçoamento de Pessoal de Nível Superior (CAPES) pelo apoio financeiro e a colaboração da Universidade Tecnológica Federal do Paraná de Ponta Grossa (UTFPR/PR) pela permissão de uso de laboratórios de panificação e de análise sensorial. Da mesma forma, agradecemos as Empresas Pinduca e Frimesa pela doação de matérias-primas para o estudo.

\section{REFERÊNCIAS BIBLIOGRÁFICAS}

ANDERSON, J.W.; JOHNSTONE, B. M.; COOK-NEWELL, M. E. Meta-analysis of the effects of soy protein intake on serum lipids. New England Journal of Medicine, Cambridge, v. 333, p. 276-282, 1995.

\section{ASSOCIATION OF ANALYTICAL CHEMISTS. Official methods of analysis of the Association of Analytical Chemists. Washington, DC, 1997.}

BAYRAM, M.; KAYA, A.; ONER, M. D. Changes in properties of soaking water during production of soybulgur. Journal of Food Engineering, Essex, v. 61, n. 2, p. 221-230, 2004. 
BOWLES, S. Utilização do subproduto da obtenção de extrato aquoso de soja-okara em pães do tipo francês. 2005. 82 f. Dissertação (Mestrado em Ciência e Tecnologia de Alimentos) - Universidade Estadual de Ponta Grossa, Ponta Grossa, 2005.

CARRÃO-PANIZZI, M. C.; MANDARINO, J. M. G. Soja: potencial de uso na dieta brasileira. Londrina: EmbrapaCNPSO, 1998. 16 p.

CIABOTTI, S.; BARCELlOS, M. de F. P.; MANDARINO, J. M. G.; TARONE, A. G. Avaliações químicas e bioquímicas dos grãos, extratos e tofus de soja comum e de soja livre de lipoxigenase. Ciência e Agrotecnologia, Lavras, v. 30, n. 5, p. 920-929, set./out. 2006.

DELla TORRE, J. C. de M.; RODAS, M. A. de B.; BADOLATO, G. G.; TADINI, C. C. Perfil sensorial e aceitação de suco de laranja pasteurizado minimamente processado. Ciência e Tecnologia de Alimentos, Campinas, v. 23, n. 2, p. 105-111, maio/ago. 2003.

DEMIATE, I. M.; CEREDA, M. P. Some physicochemical characteristics of modified cassava starches presenting baking property. Energia na Agricultura, Botucatu, v. 15, n. 3, p. 36-46, 2000.

DHINGRA, S.; JOOD, S. Organoleptic and nutricional evalution of wheat breads supplemented with soybean and barley flour. Food Chemistry, Food Chemistry, v. 77, p. 479-488, 2001

EMPRESA BRASILEIRA DE PESQUISA AGROPECUÁRIA. Embrapa. Disponível em: <http:// w w w . c n p s o.e m b r a p a b r / ind ex.ph p ? o p page=22\&cod_pai=16>. Acesso em: 16 abr. 2007.

FARIA, E. V. de; YOTSUYANAGI, K. Técnicas de análise sensorial. Campinas: ITAL/LAFISE, 2002. 116 p.

HALL, C. W. Drying farm crops. Westport: The Avi, 1971.

INSTITUTO ADOLFO LUTZ. Normas analíticas do Instituto Adolfo Lutz: métodos químicos e físicos para análise de alimentos. 3. ed. São Paulo, 1985. v. 1, 533 p.

JACKSON, C. J.; DINI, J. P.; LAVANDIER, C.; RUPASINGHE, H. P. V.; FAULKNER, H.; POYSA, V.;
BUZZELL, D.; GRANDIS, S. de. Effects of processing on the content and composition of isoflavones during manufacturing of soy beverage and tofu. Process Biochemistry, [S.1.], v. 37, p. 1117-1123, 2001.

MA, C. Y.; LIU, W. S.; KWOK, K. C.; KWOK, F. Isolation and characterization of proteins from soymilk residue (okara). Food Research International, Barking, v. 29, p. 799-805, 1997.

PEREIRA, A. J. G. Fatores que afetam a qualidade do pão de queijo. Belo Horizonte: CETEC, 1998. 52 p.

PEREIRA, J. Caracterização química, física, estrutural e sensorial do pão de queijo. 2001. 222 p. Tese (Doutorado em Ciência dos Alimentos) - Universidade Federal de Lavras, Lavras, 2001.

PEREIRA, J.; CIACCO, C. F.; VILELA, E. R.; PEREIRA, R. G. F. A. Função dos ingredientes na consistência da massa e nas características do pão de queijo. Ciência e Tecnologia de Alimentos, Campinas, v. 24, n. 4, p. 494-500, out./dez. 2004.

PLATA-OVIEDO, M. S. V. Secagem do amido fermentado de mandioca: modificação química relacionada com a propriedade de expansão e características físicoquímicas. 1998. 114 p. Tese (Doutorado em Tecnologia de Alimentos) - Universidade Federal de Lavras, Lavras, 1998.

SMITH, R. J. Characterization and analysis of starch. In: WHISTLER, R. L.; PASCHAL, E. F. Starch: chemistry and technology. New York: Academic, 1967. v. 2.

STONE, H.; SIDEL, J. L. Sensory evaluation practices. San Diego: Academic, 1993.

WALISZEWSKI, K. N.; PARDIO, V.; CARREON, E. Physicochemical and sensory properties of corn tortillas made from nixtamalized corn flour fortified with spent soymilk residue (okara). Journal of Food Science, Chicago, v. 67, n. 8, p. 3194-3197, 2002.

WANG, H. L.; CAVINS, J. F. Yield and amino acid composition of fractions obtained during tofu production. Cereal Chemistry, Saint Paul, v. 66, p. 359$361,1989$. 